\title{
QUE DEUS SEJA DEUS: A REFORMA DA TEOLOGIA
}

RESUMO: Esse trabalho pretende apresentar uma releitura da teologia de Lutero na reforma protestante que sirva de paradigma para as perspectivas teológicas das igrejas brasileiras na atualidade. 0 objetivo principal é olhar para 0 espírito combativo de Lutero, sua afronta às tentativas teológicas de dominar Deus e suas propostas de reforma da teologia como perspectivas para o pensamento teológico atual. 0 caminho de pesquisa segue novos ares de encontro às releituras sobre a reforma, Lutero e a Igreja Romana. Apresenta um olhar reconciliador, no espírito da Declaração Conjunta sobre a Doutrina da Justificação. Assim, primeiro apresenta-se o contexto em que 0 espírito combativo de Lutero questiona e se propõe reformador da teologia escolástica. Apresenta-se a tese principal centrada na afirmação: Que Deus seja Deus. Em seguida, o olhar fixa-se na reflexão de Lutero, seus conceitos sobre Deus e sobre as formas em que Deus era compreendido principalmente pela teologia escolástica e pelos entusiastas. De posse desse conhecimento será proposta a libertação do imaginário e do discurso sobre Deus, sempre em relação com as afrontas daqueles que não querem que Deus seja Deus e, por fim, uma leitura em que a tese "Que Deus seja Deus", torna-se uma afirmação e construção de um paradigma capaz de configurar principalmente a realidade religiosa. A título de conclusão, traça-se um breve paralelo com a realidade religiosa brasileira em que o fôlego de Lutero é apresentado como necessário para responder às necessidade e anseios das religiões.

PALAVRAS-CHAVE: Reforma; Deus; Lutero; Teologia.

\section{LET GOD BE GOD: THE REFORMATION OF THEOLOGY}

\begin{abstract}
A rereading of Luther's theology within the Protestant Reformation is provided so that it would be a paradigm for the theological perspectives of current Brazilian churches. Luther's combative spirit against theological attempts to dominate God and Luther's propositions for theological reform are focused as perspectives for current theological thought. Research tries to reinterpret the Reformation, Luther and the Roman Catholic Church and provides a conciliating view within the spirit of the Joint Declaration on the Doctrine of Justification. Luther's combative spirit questions and proposes the reformation of Scholastic Theology. The main thesis is centered on the statement: Let God be God. Luther's reflections are then proposed, his concept on God and the manners God is understood by Scholastic theology and by the Enthusiasts. The freedom of the imaginary and discourse on God is proposed with regard to those who refuse to see God as God. The thesis "Let God be God" is interpreted and becomes the construction of a paradigm which comprehends religious reality. A brief parallel with Brazilian religious reality is given in which Luther's theological span is presented as necessary to answer religions' needs and expectations.
\end{abstract}

KEYWORDS: Reformation; God; Luther;Theology.

\section{INTRODUÇÃO}

No primeiro centenário da reforma em que luteranos e católicos celebraram em clima ecumênico, pós Declaração Conjunta sobre a Doutrina da Justificação, assinada pela Federação Luterana Mundial e a
Igreja Católica Romana, em 1999, uma nova postura tem motivado diversas releituras de Lutero e da Igreja Romana. 0 objetivo é construir memórias capazes de propor um futuro diferente. Assim, um passo importante seria pensar em perspectivas para a teologia da reforma além dos clássicos resumos sobre os famosos 
Sola Scriptura, Sola Fide, Sola Gratia e SolusChristus ${ }^{2}$, que, com certeza, não exaurem os sentidos da reforma protestante.

Esse trabalho pretende olhar para a reflexão de Lutero no debate sobre Teologia Escolástica, em que sua intenção parece estar relacionada com a necessidade de encontrar novas perspectivas para a teologia de sua época. Para essa releitura evocar-se-á uma das teses de Lutero, proferida entre 21 de agosto e 4 de setembro de 1517: "Por natureza, o ser humano não consegue querer que Deus seja Deus; pelo contrário, quer que ele mesmo seja Deus e que Deus não seja Deus" (LUTERO, 1987, p.16).

Esse trabalho não pretende exaurir a reflexão sobre 0 debate ou sobre a teologia de Lutero e da Escolástica. 0 objetivo é encontrar padrões de reflexão, problemáticas e alternativas que possam guiar as perspectivas para pensar a teologia de nosso tempo sob o olhar contínuo de reforma.

0 método de pesquisa e apresentação pretende seguir as propostas atuais sobre Lutero, mas também olhar diretamente para os textos de Lutero e pensar sua teologia em conexão com a teologia e 0 mercado religioso brasileiro. 0 foco inicial será 0 espírito combativo de Lutero, sua forma de ver e denunciar a manipulação dos imaginários de Deus. Denúncia contra o discurso de um imaginário de Deus subjugado aos interesses, comércio e terrorismo sagrado. Lutero denuncia também 0 desespero e a culpa causados por uma teologia centrada na exaltação das capacidades humanas. Sob 0 espírito combativo de Lutero, ressaltam-se novas perspectivas para sua época que, inclusive, ainda são novas para a nossa sociedade. A compreensão de um Deus gracioso e amoroso, não dominado por imaginários opressores e que não tem comércio com a humanidade, ainda é um empreendimento válido, mesmo após 500 anos da reforma.

Assim, ao término, concluir-se-á que a reforma não acabou. Que a teologia precisa continuar sendo reformada e que 0 empreendimento de Lutero é muito atual.

\footnotetext{
Somente a Escritura, Somente a Fé, Somente a Graça e Somente Cristo (Tradução nossa)
}

\section{A TEOLOGIA PRECISA DE REFORMA}

0s ares de reforma sempre estiveram presentes na igreja. Segundo Wolff, esses ideais atravessam toda história, Tertuliano, Cipriano, Agostinho, Graciano, Mestre Eckhart, Wycliff, J. Hus, os concílios de Constança, Basiléia e outros (WOLFF, 2014, p. 534). De certa forma esses ideais eclodiram a partir do confronto com a teologia escolástica. Corrente baseada no pensamento de Aristóteles que influenciou os pensadores tomistas, escotistas e occamistas. Lutero, então professor de interpretação da Bíblia na Universidade de Wittenberg, insatisfeito com a teologia escolástica iniciou uma proposta de reforma da teologia. Para Lutero o problema era que "a teologia estava acorrentada no cativeiro da escolástica, impossibilitada de articular adequadamente a questão essencial da fé cristã, ou seja, graça e justificação, Deus em seu relacionamento com o ser humano e vice-versa" (LUTERO, 1987, p.13). Lutero usa, inclusive, uma terminologia agressiva e considera essa perspectiva teológica como sendo "inimiga da graça" (LUTER0, 1987, p.13).

Lutero não era contrário ao pensamento de Aristóteles. A Escolástica, vertente principal da filosofia medieval em contexto europeu, desenvolveu suas proposições a partir de estudos nas obras de Aristóteles e Platão. Tomás de Aquino (1225-12742), reconhecido como o principal expoente da teologia escolástica, desenvolveu diversas aproximações entre a filosofia de Aristóteles e o pensamento cristão. Lutero não era contrário ao estudo de Aristóteles, inclusive, lecionou a obra Ética a Nicômaco, de Aristóteles, o que fortaleceu suas crenças (WESTHELLE, 2008, p.64,63). Entretanto, para Lutero não era possível aceitar o ideal ético aristotélico de que o justo se torna justo ao praticar atos de justiça. Muito menos aceitar a famosa regra do meio de Aristóteles (ARISTOTELES, 2004, p. 46-48), que concedia ao ser humano parte importante no processo da salvação. Essa lógica apoiava a proposta de barganha com Deus. A salvação traduzida por ideais econômicos e jurídicos, apresentada por Anselmo no século XI em Cur Deus homo ${ }^{3}$, como possibilidade de pagamen-

3 Por que Deus se fez homem? (Tradução nossa) 
to pelos nossos pecados. Para Lutero, a consequência direta dessa teologia era um clima de medo, terror e culpa sobre a humanidade.

Essa noção de satisfação da culpa/pecado levava a humanidade para a ilusão de que, ao cumprir os mandamentos, seria capaz de um amor puro para com Deus (WATSON, 2005, p.33). Era o princípio aristotélico "os iguais se reconhecem" aplicado à relação entre Deus e os homens. Um "comércio" com Deus (LOEWENICH, 1988, p.27), no qual o mundo seria dividido entre os que eram amados por Deus, porque guardavam suas leis na "prática" das obras meritórias, e os que não eram amados por Deus, por serem pecadores (LUTERO, 1993, p. 46). Para Lutero, 0 engodo estava claro. Todos somos pecadores e, nenhum ato de justiça pode nos transformar em justos, mas na melhor das hipóteses, simultaneamente justos e pecadores. Nenhum pagamento, nenhum ato de justiça poderia mudar nossa natureza de pecadores e, por isso, para Deus não há divisão, não há acepção, todos são pecadores iguais perante Deus. Não há uma relação meritória para com Deus, apenas uma relação de graça.

Adornado com essa graça, e tendo se tornado dessa maneira aceitável a Deus (gratia gratum faciens) o homem poderia começar a realizar obras meritórias no mais estrito sentido (meritum de condigno) graças às quais ele se tornara digno de reivindicar a vida eterna [...] (WATSON, 2005, p. 34).

Para Lutero, a reforma da igreja também era reforma da teologia. Ele identificou que a teologia centrada na autojustificação levava a humanidade a "uma falsa convicção de salvação" (LUTERO, 1993, p.46), a uma realidade egoísta centrada na classificação, na eleição de si mesmos e no endeusamento do humano assentado sobre trono de Deus. A essa postura, ainda atual, que Karl Barth chamou Torre de Babel.

Não há nenhum "estilo de vida" - mesmo que seu éthos fosse da mais alta qualidade - no qual, p.ex., ocorra uma unificação da vontade divina com a vontade humana ou, vice-versa, uma di- luição da segunda na primeira, um preenchimento da primeira pela segunda [...] aí não se trata do reino de Deus, mas da torre de Babel (BARTH, 2016, p. 426).

Essa teologia, centrada na capacidade humana de agradar a Deus pelas boas obras, favoreceu os sistemas de segregação, violência, legitimação e exploração dos mais fracos. Deve-se também somar a essa conta toda a violência colonizadora nas Américas, África, Ásia, Índia, Austrália. 0 empreendimento "evangelizador" na realidade ocultava interesses dominadores e exploradores. Em território brasileiro uma das primeiras teologias ensinadas aos índios era sobre o pecado o Diabo e o Inferno. Medo necessário para se manter o controle e subjugação (CHAMORRO. 2004, p.207).

Em Lutero, a leitura era outra. No Debate sobre Teologia Escolástica, Lutero desafiou a teologia bíblica e sistemática, e foi da fagulha ao fogo com questões cuja atualidade é indiscutível. 0 desafio de aprender a ler a realidade a partir das influências teológicas e filosóficas de nossa época. 0 desafio de precisar quais sistemas e filosofias desvirtuam a sociedade. Desafio de, a partir da fé cristã, defender e enfatizar 0 que é essencial na vida, inclusive pelo combate às tendências verdadeiramente idólatras, não por recriminar imagens, mas por transformar o homem em Deus, dando-Ihe o direito de legislar sobre salvação e condenação, idolatria que assentou o humano no trono de Deus, como um Não-Deus (BARTH, 2016, p.84), um deus pequeno, criado e controlado pelo fazer teológico. Em Lutero era uma teologia contra a teologia. 0 fôlego de Lutero nos desafiou a lutar contra toda teologia que, pela possibilidade de comércio e barganha com Deus, incute terror, manipula e explora. 0 desafio de produzir uma teologia capaz de libertar as pessoas da ilusão e, principalmente, do controle político-religioso.

\subsection{O DESAFIO DE REFORMAR O IMAGINÁRIO DE DEUS: JUSTO E AMOROSO}

Na teologia escolástica, a exaltação das capacidades humanas estabelecia metas inatingíveis que 
oprimiam àqueles que pretendiam ser fiéis (WATSON, 2005, p.33). Como pecadores podem agradar a Deus? Os pecadores estão sempre sob o juízo e medo, constatação em que Lutero afirmava: no "mero pronunciamento do nome de Cristo, meu coração se agitava e tremia de medo, pois eu estava persuadido de que ele era um severo juiz" (WATSON, 2005, p.37). Teologia de onde Lutero, antes de seu encontro com o Deus gracioso, pronunciou veementemente: "0 meu pecado, meu pecado, meu pecado!" (WATSON, 2005, p.40). Revela, assim, a crueldade da ênfase nos méritos, porque abandona o ser humano à sua própria sorte, que, sendo "árvore má" (LUTERO, 1987, p.15), não de forma determinista e opressora, mas, de forma natural e consequente, sempre está debaixo do juízo. Não sob a “justiça dos hipócritas" (LUTERO, 1987 p.19), mas sob a crise de Lutero: "Como Deus pode ser justo e, ainda assim, ser amoroso?" (WESTHELLE, 2008. p.63).

A própria crise de Lutero apontava a solução. A teologia precisava de uma reforma na imagem de Deus. Assim, nos Evangelhos, Lutero encontrou o Deus gracioso que perdoa e aceita a pessoa, mesmo sendo indigna e pecadora (WATSON, 2005, p.43), enfatizando que "Da parte do ser humano, entretanto, nada precede à graça senão indisposição e até mesmo rebelião contra a graça" (LUTERO, 1987, p.16).

Essa imagem de um Deus gracioso também foi comunicada nos hinos, como se vê na quinta estrofe do hino 143 de Lutero no hinário da IECLB: "Se mil pecados em nós há, em Deus há mais piedade, e sua mão ajudará em trevas, dor, maldade. Só ele é nosso bom pastor que salvará, por seu amor, seu povo dos pecados" (FISHER, 1981, p50). Para Lutero, 0 amor de Deus não parte de nenhum mérito nosso, mas única e exclusivamente da graça, é um amor que "não acha, mas cria aquilo que the agrada" (LUTER0, 1987, p.39). Essa teologia, diferente da escolástica, era portadora de grande consolo, pois ensinava que a "esperança não vem dos méritos, mas de sofrimentos que destroem os méritos" (LUTER0, 1987, p.16).

É em todos os sentidos uma palavra evangélica e um dulcíssimo consolo para os míseros pecado- res a passagem em que Ezequiel diz: "Não quero a morte do pecador, mas, sim, que ele se converta e viva" [33.11]. 0 mesmo vale para SI 29.6: "Porque sua ira dura um momento, e sua vontade é, antes, a vida". E SI 69.17: "Quão benigna é tua misericórdia Senhor!" Igualmente: "Vinde a mim todo os que estais afadigados, e eu vos reanimarei". Do mesmo modo Êxodo 20.6: "Eu faço misericórdia em muitos milhares àqueles que me amam". E o que é quase metade da Sagrada Escritura senão puras promessas de graça, pelas quais Deus oferece misericórdia, vida, paz e salvação aos seres humanos? Que outra coisa, porém, dizem as palavras de promessa senão isso: "Não quer a morte do pecador?" Acaso dizer: "Eu sou misericordioso" não é a mesma coisa que dizer: "Não me iro, não puno, não quero que morrais, quero perdoar, quero poupar"? E se não ficassem de pé aquelas promessas divinas por meio das quais se animam as consciências aflitas pela percepção do pecado e aterrorizadas pelo medo da morte e do juiz, que lugar haveria para o perdão ou a esperança? Qual 0 pecador que não desesperaria? [...]" (LUTER0, 2000, p.99).

Lutero apresentou mais que um novo conceito de Deus, era uma nova proposta de relacionamento com Deus (WATSON, 2005, p. 43). Não apenas 0 Deus terrível e distante, mas também o Deus próximo e misericordioso, justo e amoroso. Não uma tensão entre o terrível e o misericordioso, mas complementaridade. Um Deus para todos, que ama, aceita, perdoa e justifica àqueles que são ao mesmo tempo justos e pecadores. A ausência dessa complementaridade na teologia torna Deus um juiz severo legitimador de minorias religiosas que sem perceber sua hipocrisia se julgam superiores por suas práticas de justiça, no direito, inclusive, de passar por cima do próximo (FISHER, 1981, p. 58) de forma classificatória, num ecletismo baseado em falsa santidade que exclui e condena os "pecadores".

A concepção de Lutero não afrontava apenas a teologia, ou a igreja com suas políticas, mas, era uma 
afronta a todo elitismo classificatório e excludente que se arrojava como necessário para construção do reino de Deus na terra (FISCHER, 1981, p. 62). Nesse ponto é preciso entender que suas afrontas se direcionaram também contra alguns companheiros da reforma que, em sua radicalidade, reproduziam 0 imaginário opressor de Deus. A reforma da teologia foi uma afronta à manipulação religiosa do imaginário de Deus com vistas a legitimações particulares. Era a denúncia da fraqueza teológica e ideológica de tal empreendimento. Era a defesa do povo, dos excluídos. 0 fim das distinções qualitativas pela proclamação de que todos somos pecadores, que nenhum mérito precede a graça, de que ninguém precisa se sentir culpado e condenado, pois ninguém é capaz de fazer apenas 0 bem para agradar a Deus. Afirmação de que todos têm 0 mesmo acesso direto a Deus pela graça manifesta por Jesus Cristo (FISHER, 1981, p. 66). A afirmação de que não somos Deus e que o melhor para nós é deixar que Deus seja Deus.

\subsection{QUE DEUS SEJA DEUS: 0 DESAFIO DE LIBERTAR 0 DISCURSO SOBRE DEUS}

No debate contra a teologia escolástica, Lutero produziu 97 teses. Da 5 até a 36 , contra a capacidade natural do ser humano, da 37 até a 53, contra a concepção de justiça e influência de Aristóteles, da 54 a 97 sobre a relação entre graça, obediência e livre arbítrio (LUTERO, 1987, p. 14). Sua acusação não estava direcionada à igreja ou às estruturas políticas, mas apontava para um edifício teológico construído sobre pressupostos que impediam Deus de ser Deus, afirma que "Por natureza, 0 ser humano não consegue querer que Deus seja Deus; pelo contrário, quer que ele mesmo seja Deus e que Deus não seja Deus" (LU_ TERO, 1987, p. 16).

Na tese acima, Lutero defendeu que 0 imaginário de Deus dominado pelas estruturas de poder, sejam religiosas ou filosóficas, procurava sempre definir, compreender e aprisionar Deus. Segundo Barth, quando nos aproximarmos de Deus, puxamos Ele para próximo de nós e o transformamos de acordo com nos- sas vontades em um Não-Deus (BARTH, 2016, p.87). Toda teologia que compreende Deus é uma forma de controlar o discurso sobre Deus. Assim, rapidamente a questão não era apenas teológica, mas ideológica, de domínio e controle. No confronto com Erasmo, por exemplo, Lutero afirmou que o imaginário de Deus foi aprisionado pela teologia. Deus só está onde os teólogos permitem que esteja (LUTERO, 1993, p. 37), reflexão que continua se reproduzindo até nossos dias. Para Lutero, ninguém tinha/tem o direito de "prender a doutrina cristã a lugares, pessoas, tempos e situações, quando Cristo quer que ela, libérrima, seja divulgada e reine no orbe" (LUTERO, 1993, p. 39).

Naturalmente teu Criador apren-
derá de ti; criatura sua, o que é
útil e o que é inútil pregar, e aquele
Deus estulto ou ignorante até ago-
ra não sabia o que deve ser ensi-
nado, até que tu, seu mestre, Ihe
prescrevesses o modo de saber e
de mandar, como se ele ignorasse,
se tu não lho ensinasses [...] (LU-
TER0, 1993, p. 44).

Em virtude disso, Lutero tanto insistiu no Deus absconditus, não dominado pelo conhecimento humano. Ou seja, a fé é possível apenas quando aquilo em que se crê seja absconditus (LUTERO, 1993, p. 47). 0 princípio era que as coisas de cima, no céu, não competem ao homem, Ihe são abscônditas, para que possa voltar-se para Deus com fé. Essa ação de graça pelo ocultamento é relacionada por Lutero com o termo de Isaias 28.21, a "obra estranha de Deus", em que pelo reconhecimento de nossa fraqueza e humilhação diante da lei como pecadores dispõe-se para nós 0 caminho da graça de Deus. É a teologia paulina em 1Corintios, tão cara a Lutero, que afirma a sabedoria dos homens como inferior à loucura de Deus. Ou seja, a graça de Deus não está condicionada por nenhuma lógica humana, e por isso, pode e oferece a si mesma até no lugar mais improvável, "assim, quando vivifica, Deus 0 faz matando, quando justifica, 0 faz incriminando, quando leva ao céu, o faz conduzindo ao inferno, como diz a Escritura: "0 Senhor mata e vivifica, leva ao inferno e retira (1Sm 2.6)" (LUTER0, 1993, p. 
47). Esse ocultamento, lido por Lutero como liberdade de Deus e insuficiência do homem é a libertação do discurso sobre Deus. Não há, portanto, espaço para lógica ou obras humanas. Não significa que Deus seja arbitrário, mas, que Ele não é dirigido por lógica humana ou religiosa, pois, "Se, portanto, eu pudesse, de algum modo compreender de que maneira é misericordioso e justo esse Deus que mostra tão grande ira e iniquidade, a fé não seria necessária. Agora, como não se pode compreender isso, há lugar para exercitar a fé [...]" (LUTERO, 1993, p. 47).

Ao afirmar a possibilidade de Deus ser Deus, Lutero aspira à libertação do imaginário de Deus do discurso teológico, principalmente das manipulações religiosas, abrindo espaço para a inclusão e fé. Entretanto, 0 ser humano não quer que Deus seja Deus, porque precisa se sentir seguro, assim, cria mecanismos religiosos ou práticos de autoafirmação da salvação ou de negação das formas de condenação. 0 principal mecanismo é a teologia. Para Lutero, um mundo sem Deus, não é um mundo sem fé, mas um mundo que criou um sistema de crenças que aliena as pessoas de Deus, seja criando um falso Deus que os aprove, ou negando toda ideia de condenação que possa vir de Deus. Em ambos os casos prende-se 0 imaginário de Deus em um discurso teológico. Contra esse discurso é preciso deixar "Que Deus seja Deus!".

\subsection{DESAFIO DE ACEITAR QUE DEUS SEJA DEUS}

Além de tentar definir o discurso sobre Deus, há uma tendência de impedir que Deus seja Deus. Essa tendência pode ser vista no texto de Mateus 23:13 "Ai de vós, escribas e fariseus, hipócritas, porque fechais 0 reino dos céus diante dos homens; pois vós não entrais, nem deixais entrar os que estão entrando". A consequência de se criar um sistema de crenças legitimador é a elaboração de uma lógica de comércio vinculada ao que se está legitimando. Dessa forma, a teologia escolástica não apenas delimitou 0 agir de Deus, mas, inclusive, estabeleceu os padrões para decidir quem era aprovado ou reprovado, quem poderia ou não entrar no reino dos céus. Prática essa que perdura até a atualidade, oculta em formas teológicas legitimadoras que operam nas mais diversas expressões de fé.

Para Karl Barth "o pequeno Deus necessita dispensar razoavelmente 0 grande Deus" (BARTH, 2016, p. 88). Uma teologia que usa a imagem de Deus para legitimar um ideal igualmente nega/restringe toda a ação de Deus que não Ihe corresponda. Como num leito do rio, onde aqueles que moram na região ribeirinha tentam represá-lo para que outros não recebam suas águas (BARTH, 2016, p. 105-106). Mas na denúncia de Lutero, Deus não está limitado por nenhuma teologia/ideologia, não pode ser represado, ele é Deus. A represa é o pequeno Deus, criação ideológica, o Não-Deus. 0 Eu disfarçado de Deus, vestido de Deus de forma que me identifico com Ele e passo a conhecê-lo intimamente. Sua vontade, seu agir e seu querer, isso porque transformo Deus segundo a minha imagem (BARTH, 2016, p. 84).

Essa denúncia contra a teologia escolástica também se estendeu aos grupos de reformadores radicais, denominados Entusiastas. A radicalidade desse grupo reformador fez com que 0 imaginário de Deus também fosse subjugado. Imbuídos da necessidade de reforma, negaram e condenaram todo conhecimento de Deus que fosse diferente. Não se diferenciaram da teologia que perseguiram. Traziam 0 discurso do opressor dentro de si. Inclusive igualaram-se na tentativa de impor seu ideal. Novamente o pequeno Deus surge ao afirmar sua vontade, seu agir e 0 seu querer, como se fosse 0 grande Deus.

\begin{abstract}
Neste caso 0 entusiasmo manifesta-se como a atitude e disposição de, na certeza de ter reconhecido a verdade do evangelho e a vontade de Deus, passar por cima do próximo, de obrigá-lo a aceitar o que, conforme minha convicção, é para o seu bem [...] Isso significa que na vida da fé uma minoria poderia dominar a maioria (FISHER, 1981, p. 58).
\end{abstract}

Não querer que Deus seja Deus equivale a negar a graça. Se incomodar com a salvação e inclusão do outro, perder o domínio. Em minhas aulas na carta 
aos Romanos, vários estudantes parecem surtar com a possibilidade da graça como salvação para todos. É comum ouvir expressões como "não vamos condenar ninguém?" ou, "assim, o inferno vai ser saqueado!". A graça incomoda porque rompe com o elitismo e com a ideia de que minha religião me faz melhor que 0 outro. Os Entusiastas, por exemplo, chegaram a legislar em nome de Deus e afirmar que "um ateu não tem direito à vida" (FISHER, 1981, p. 61). A estes, diziam, não se dirija nem palavras cordiais, nem hospedá-los em casa e, radicalmente, nem tratá-los como humanos, pois 0 fato de terem a pele como a nossa não os faz nossos irmãos (FISHER, 1981, p. 64). A autojustificação torna-se, não apenas em legitimação, mas em exclusão, julgamento e condenação dos diferentes. Não é surpresa que tantas expressões de violência, de tantas formas, sejam fruto de extremismo religioso.

A teologia quando preocupada em legitimar 0 controle sobre os fiéis, torna-se um simulacro e rouba o sentido de Deus, coloca-se como o pequeno deus, e por fim não suporta que Deus haja com graça. Não permite que Deus ame, que seja misericordioso, que trate a todos sem acepção. Não quer que Deus seja Deus.

\subsection{DESAFIO DE SUPERAR O COMÉRCIO PELA JUS- TIÇA DE DEUS}

Olhar a reforma a partir dos conflitos, sejam teológicos ou políticos, torna-a algo mesquinho, briga política por poder. Olhada pelo prisma intelectual dos quatro Sola, torna-se apenas discussão teológica. 0 olhar deve ser mais amplo. Lutero, por exemplo, viu uma perspectiva elitista de domínio e exclusão no conceito aristotélico de justiça. Exclusão que sentiu na pele, pela construção do olhar do oprimido através dos olhos do opressor. Por isso, ao olhar o conceito de pecado, não viu uma segregação de pecadores condenados. Pelo contrário, na afirmação de que todos somos pecadores, Lutero viu que o pecado não nos diferencia, antes, nos iguala. Torna a todos reprovados. Essa é a justiça de Deus, pois, quando aceitamos que todos somos pecadores, somente Deus pode nos tornar justos.
Não há preferência, não há meritocracia, não há "satisfação por seus pecados" (LUTERO, 1987, p. 33), não há comércio com Deus, não há filhos prediletos, não há foro privilegiado. Não há obras anteriores ou posteriores que tornem alguém digno, "Pois os pecadores são belos por serem amados, e não são amados por serem belos" (LUTER0, 1987, p. 53).

Do contraio, no comércio da fé é o medo de Deus que se cultua. Não há espaço para o Deus de amor e, nas teologias cristãs em que Cristo morre para pagar por nossos pecados a graça e o perdão não subsistem, pois onde há pagamento já não há graça.

Nesse contexto, para Lutero o pecado é visto como desespero de si mesmo e ao mesmo tempo como "[...] esperança que é pregada quando se nos prega que somos pecadores" (LUTER0, 1987, p. 48), que "todos tem um coração obscurecido" (LUTERO, 1993, p. 26). Quando olhamos para o pecado da perspectiva do deus pequeno nos desesperamos diante de nossa incapacidade, a graça não se manifesta e a religião surge como ilusão de superação. 0 homem continua escravo do pecado e das estruturas de poder. Apenas quando olhamos para o pecado da perspectiva do grande Deus, encontramos verdadeira esperança na graça, amor e perdão, sem jugo, sem elitismo, sem preferências. Pois, a perspectiva de Deus é clara: "Deus não quer a morte do pecador" (LUTER0, 1993, p. 99).

Olhar a justiça e o pecado nos conduz ao amor, graça e perdão de Deus. Não precisamos buscar satisfação pelos pecados se "Deus os perdoa a toda hora grátis, por graça inestimável, e nada deseja em troca senão que doravante se leve uma vida boa" (LUTERO, 1987, p. 33). A diferença principal está no amor de Deus que cria o que Ihe agrada, não sendo condicionado pelo objeto, como 0 amor humano (LUTERO, 1987, p. 39). Em Lutero, o objetivo de Deus é a misericórdia (LUTER0, 1993, p. 100) pois é "disso que se trata o Deus pregado: que o pecado e a morte sejam tirados e nós sejamos salvos" (LUTER0, 1993, p.101). Deixar que Deus seja Deus é aceitar o que Jonas negava, que Deus é clemente e misericordioso, tardio em irar-se e grande em benignidade, e que se arrepende do mal (Jn 4.2). 
Nesse olhar há esperança, porque a confiança está em Deus, enquanto na teologia que depende da justiça humana reina 0 desespero da impossibilidade. Parafraseando Barth, de nós para Deus, somos sempre reprovados como Saul, mas de Deus para nós, somos sempre aprovados como Jacó (BARTH, 2016, p. $363)$. Na graça pode até ser que o pecado nos afaste de Deus, mas não tem poder para afastar Deus de nós.

\section{CONSIDERAÇÕES FINAIS}

Diante desse breve testemunho dos ares e fagulhas teológicas da reforma, resta-nos, a título de balanço, um confronto com o olhar de Lutero.

A primeira impressão que se tem é de que a reforma iniciou um processo constante de crítica às estruturas religiosas. 0 que se comprova pela diversidade e amplitude dos cristianismos por todo o mundo. Sem dúvida 0 espírito combativo e crítico de Lutero foi assimilado e transmitido muito além das portas de Wittenberg. Entretanto percebe-se também que a lógica estrutural dominadora e exploradora que Lutero afrontou também permanece, confundindo o próprio sentido de igreja.

A partir do exposto, temos a certeza de que 0 empreendimento de Lutero ainda não terminou. A reforma continua. Ecclesia Reformata et Semper Reformanda est, (A igreja Reformada está sempre se Reformando). Necessidade que se faz presente na realidade brasileira, principalmente para os novos movimentos que pouco conhecem de Lutero e da reforma protestante.

Um breve olhar sobre a atualidade das igrejas no Brasil revela a presença de elementos ideológicos de dominação do imaginário de Deus. A centralização do indivíduo, característica marcante da modernidade, reforça a presença do pequeno Deus que continua sendo construído para legitimação da própria salvação. Teologias legitimadoras, elitistas e excludentes são reproduzidas em diversas comunidades. 0 comércio com Deus tem sido incentivado, inclusive pelas mídias sociais. 0 perdão para os pecados pode ser facilmente encontrado em prateleiras do mercado religioso nacional. A tendência de se identificar com Deus para legislar e impor a vontade de Deus continua. Ideais de conquista e dominação herdados do imperialismo na invasão espanhola e portuguesa se confundem com expansão missionária. Atos de intolerância, ao estilo dos entusiastas, são noticiados diariamente em uma nação, cujo Estado se professa laico. Imposição e evangelização a força procuram dominar o Estado pela política para criar o reino de Deus, empreendimento que na verdade parece-se mais com a construção da Torre de Babel. Um simples olhar é suficiente para perceber as fagulhas da reforma presentes na atualidade, o que nos falta são pulmões dispostos a respirar os ares de Lutero.

As teses de Lutero sob o contexto da reforma precisam voltar a ser respiradas. A teologia precisa continuar sendo reformada. É preciso combater as teologias que se põem como inimigas da graça. 0 desafio de olhar além, de perceber as influências externas, as lógicas e filosofias que são usadas de base para construção teológica. A teologia precisa exercer a vigilância contínua em reformar os imaginários de Deus, que constantemente são maculados pelos discursos de poder e controle.

Imaginários do Deus Terrível, Vingativo, Destruidor, Violento, inundam pregações e comunidades perpetuando dominação e exploração pelo medo. Reformar 0 discurso e 0 imaginário é assumir a revelação de Deus nos evangelhos como centro da mensagem cristã. A revelação do Deus gracioso e amoroso precisa superar a revelação do Deus Terrível.

É preciso que a teologia aceite que Deus seja Deus. Que abra mão do controle e da manipulação dos imaginários. A religião que usa a teologia para exercer controle sobre os imaginários de Deus precisa ser repensada. 0 pequeno Deus precisa ser confrontado com o grande Deus, para que possamos ser salvos do desespero do mercado religioso e encontrar abrigo na graça do grande Deus. Somente sob o grande Deus nos tornamos mais tolerantes, pois reconhecemos que todos somos pequenos e pecadores, afastando-nos da ilusão de controle. 
A luta contra 0 imaginário opressor de Deus é principalmente uma luta contra o comércio e barganha com e pelo Sagrado. Pois um Deus gracioso e misericordioso que ouve a todos, em qualquer lugar sem distinção e discriminação, não precisa de intercessores e mediadores, ministros de barganha e comércio com Deus. É preciso superar o comércio opressor que abandona a humanidade a mercê do terror e da culpa e reconhecer a fraqueza humana como base para a justiça de Deus que se revela de graça pelo amor, destruindo 0 terror e a culpa.

Quando afirmarmos que tudo e todos pertencem a Deus, que os limites para salvação e condenação são construções ideológicas das religiões, que nenhum conhecimento, prática, confissão ou lógica, nos dá méritos ou deméritos diante de Deus, que todos somos igualmente amados por Deus, seremos capazes construir um futuro diferente, mais tolerante e mais igualitário. Com essa fé não há motivos para divisões, perseguições e intolerância. Apenas a convicção de que as coisas do céu não nos competem. $A$ nós está apenas a vida.

Assim, ao modo de Lutero, precisamos nos comprometer a não querer ser Deus, mas deixar que Deus seja Deus!

\section{REFERÊNCIAS}

ARISTOTELES. Ética a Nicômaco. São Paulo: Martin Claret, 2004.

BARTH, K. A Carta aos Romanos: Segunda versão (1922). Editado por Cornelis van der Kooi and Katja Tolstaja. traduzido por Uwe Wegner. São Leopoldo: Sinodal, 2016.

CHAMORR0, G. Teologia Guarani. Quito, Equador: Abya-Yala, 2004.

FISCHER, J. 0 Homem: um Entusiasta? a atualidade do tema Lutero e os entusiastas. In. DREHER, M. N. Reflexões em torno de Lutero. São Leopoldo: Faculdade de Teologia, 1981.
LOEWENICH, W. von. A Teologia da Cruz de Lutero. São Leopoldo: Sinodal, 1988.

LUTERO, M. Debate sobre Teologia Escolástica. In: OBRAS Selecionadas. São Leopoldo: Sinodal; Porto Alegre: Concórdia. 1987. Vol 1.

LUTERO, M. Da vontade Cativa. In: OBRAS Selecionadas. São Leopoldo: Sinodal; Porto Alegre: Concórdia. 1993. Vol 4.

LUTERO, M. Debate de Heidelberg. In: OBRAS Selecionadas. São Leopoldo: Sinodal; Porto Alegre: Concórdia. 1987. Vol 1.

WATSON, P. S. Deixa Deus ser Deus. Canoas: Ulbra, 2005.

WESTHELLE, V. 0 Deus escandaloso: usos e abusos da cruz. São Leopoldo: Sinodal, 2008.

WOLFF, E. Reformas na igreja: chegou a vez do catolicismo? Uma aproximação dos 50 anos do Vaticano II e os 500 anos da reforma luterana, no contexto do pontificado do Papa Francisco. Horizonte, Belo Horizonte, v. 12, n. 34, p. 534-567, abr./jun. 2014.

Recebido em: 29/04/2018

Aceito em: 12/06/2018 